\title{
STUDI FITOPLANKTON DI DANAU TONDANO PROPINSI SULAWESI UTARA
}

\author{
Gaspar Manu, Martinus Baroleh, Alex Kambey \\ Staf Pengajar pada Program Studi Manajemen Sumberdaya Perairan, \\ Fakultas Perikanan dan IImu Kelautan. UNSRAT. Manado 95115.
}

\author{
ABSTRACT \\ Manu, G., M. Baroleh, A. Kambey. 2010. \\ The Study on Phytoplankton in Tondano Lake North Sulawesi. \\ Jurnal Perikanan dan Kelautan. Vol VI (1): 13-17.
}

\begin{abstract}
Research was conducted in Tondano Lake North Sulawesi for 3 month from June to August 2007. The research was aimed to identify species abundance of phytoplankton. Phytoplankton were collected a $40 \mu \mathrm{m}$ large plankton net.

Results showed that phytoplankton consisted of 32 genera. It also indicated that the highest individual abundance was Fragillaria (2903 ind), followed by Microspora (2349 ind), Closterium ( 984 ind), Zynema (803 ind), Melosira (770 ind), and Anabaena (693 ind) respectively with monthly sampling the highest abundance was on August (4227 ind), followed by June (3516 ind), and July (3493 ind).
\end{abstract}

Keywords: Tondano Lake, Phytoplankton, Abundance.

\section{PENDAHULUAN}

Danau Tondano adalah danau yang terletak di daerah Kabupaten Minahasa Induk dan merupakan danau terluas di Propinsi Sulawesi Utara, dengan luas 5600 $\mathrm{Ha}$ dan terletak pada ketinggian 650 meter di atas permukaan laut (KLH, 2006). Danau Tondano berada di daerah tangkapan hujan (catchment area). Danau Tondano yang dialiri oleh 25 sungai, 4 sungai diantaranya berukuran cukup besar sedangkan yang lainnya berukuran kecil bahkan beberapa diantaranya mengalami kekeringan pada musim kemarau yang panjang. Danau Tondano mendapat aliran air dari sungai-sungai dan dari saluran irigasi serta saluran pemukiman penduduk. Danau Tondano hanya mempunyai satu aliran air keluar danau (out let) yang menuju sungai Tondano serta melewati kota Tondano dan bermuara di Teluk Manado.

Danau Tondano mempunyai arti penting dan strategis bagi pelaksanaan pembangunan di wilayah propinsi Sulawesi Utara karena memiliki multi fungsi sebagai: (1) sumber pembangkit listrik tenaga air (PLTA) Tanggari; (2) sumber air minum (PDAM Manado); (3) sumber air bagi kepentingan pertanian; (4) tempat menangkap ikan; (5) tempat memelihara ikan; (6) daerah pariwisata; dan (7) transportasi air.

Seiring dengan pertumbuhan penduduk yang pesat di sekitar danau menimbulkan permasalahan bagi lingkungan danau, berupa sedimentasi oleh karena pemanfaatan hutan dan berbagai penggunaan lahan di Daerah Aliran Sungai. Perubahan kualitas air mengakibatkan peningkatan hara (eutrofikasi) oleh aktifitas pemupukan lahan pertanian dan pakan yang bersumber dari jaring apung. Peningkatan nutrient tersebut menyebabkan meningkatnya fitoplankton dan gulma bertumbuh pesat. Eutrofikasi dan perubahan kualitas air akan terus terjadi dan meluas sepanjang tahun bila tidak dilakukan pengelolaan/pemulihan terhadap kerusakan Ekosistem Danau Tondano.

Danau Tondano yang hanya memiliki satu outlet dengan 25 sungai yang bermuara ke danau sebagai inlet, akan mengalami eutrofikasi dalam waktu yang panjang bila bahan penyebab eutrofikasi terus masuk dan menumpuk dalam air 
danau. Kondisi danau seperti ini akan membutuhkan waktu yang sangat panjang untuk terjadinya pergantian air secara keseluruhan yang dikenal dengan hydraulic retention time.

Danau yang mengalami eutrofikasi seperti danau Tondano akan diikuti pula oleh pertumbuhan fitoplankton. Dengan demikian pemantauan terhadap keberadaan fitoplankton khususnya dalam hal kelimpahan genera perlu dipantau secara berkesinambungan. Hal ini perlu dilakukan mengingat fitoplankton merupakan penentu dalam kelangsungan ekosistem dari danau tersebut, mengingat fitoplankton merupakan produser primer dalam rantai makan.

Hal utama yang perlu diperhatikan dalam penelitian lingkungan perairan adalah produktivitas primer (fitoplankton) dan total biomassa plankton. Banyak pengaruh aktivitas manusia yang terjadi secara simultan menghasilkan perubahan kondisi lingkungan, seperti perbedaan biologi dan struktur tropik dari komunitaskomunitas organisme itu sendiri, termasuk plankton sebagai sumber produktivitas primer di danau Tondano.

Hasil penelitian UCE-CEPI bekerja sama dengan PPLH Unsrat di tahun 2001 dalam Kumurur 2002, menyatakan bahwa daerah aliran sungai (DAS) Tondano telah mengalami degradasi lingkungan. Kegiatan pembangunan pada sektor pertanian, industri, kehutanan, perikanan, dan pariwisata selain menghasilkan sesuatu yang positif bagi manusia yang memanfaatkannya juga menimbulkan dampak negatif terhadap estetika dan ekosistim danau Tondano (Kumurur, 2002). Keberadaan perairan danau Tondano terus mengalami tekanan sehingga sangat disayangkan jika hal ini terus terjadi secara berkelanjutan dari tahun ke tahun dan akan berdampak buruk bagi ekosistem danau. Seperti keberadaan jenis fitoplankton yang diinformasikan terdiri dari 55 jenis (Ratag, 1981; Rondo dan Soeroto, 1990). Dalam Soeroto,.dkk, 1999 menginformasikan terdapat 48 genera fitoplankton di tahun 1981, dan ditahun 1999 tinggal 40 genera fitoplankton yang ditemukan di danau Tondano.

\section{TUJUAN PENELITIAN}

Tujuan Penelitian adalah untuk: (1) menginventarisir genera fitplankton dan (2) Menganalisis kelimpahan dari fitoplankton.

\section{METODE PENELITIAN}

\section{Lokasi dan Waktu Penelitian}

Penelitian ini dilakukan di danau Tondano Daerah Kabupaten Minahasa Induk Propinsi Sulawesi Utara (Gambar 1). Penelitian berlangsung selama 3 bulan terhitung mulai bulan Juni hingga Agustus 2007.

\section{Bahan dan Alat}

Bahan yang digunakan untuk mengawetkan fitoplankton yaitu lugol. Alat yang digunakan dalam penelitian ini adalah plankton net, botol sampel, kamera dan mikroskop.

\section{Pengambilan Sampel}

Pengambilan sampel dilakukan sekali dalam sebulan pada setiap lokasi penelitian.

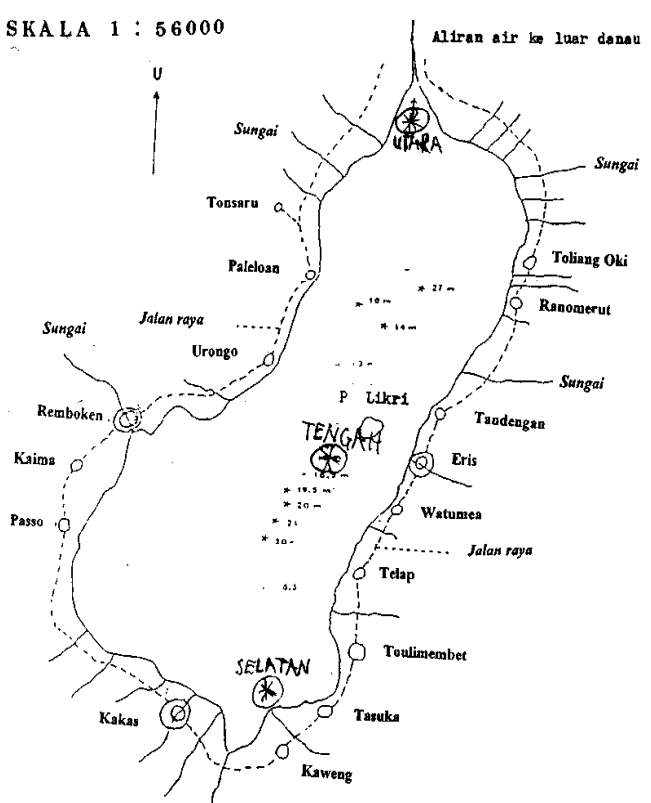

Gambar 1. Peta Lokasi Penelitian Sumber : Dinas Pekerjaan Umum Dirjen Sumberdaya Air (2006). 
Sampel diambil dengan menggunakan plankton net dengan ukuran mata jaring 40 $\mu \mathrm{m}$ dan diameter mulut jaring $20 \mathrm{~cm}$.

Cara pengoperasian plankton net yaitu dengan mengatur posisi plankton net berada pada kolom air sedalam $20 \mathrm{~cm}$ dari permukaan air. Kemudian dengan bantuan perahu, plankton net ditarik sepanjang 10 meter. Air yang tersaring pada plankton net (cod end sebanyak $30 \mathrm{ml}$ ) selanjutnya dimasukan dalam botol sampel yang diberi pengawet lugol. Selanjutnya sampel tersebut dibawa ke Laboratorium HBMSP untuk diamati. Untuk menentukan jenis fitoplankton, sampel diamati di bawah mikroskop kemudian diidentifikasi dengan menggunakan petunjuk Sachlan, (1972); Apha, (1985); Needham dan Needham, (1963); dan Davis, (1955). Identifikasi dilakukan dengan cara mencocokan sampel dengan gambar yang ada pada buku identifikasi.

\section{Analisan Data}

Untuk menghitung kepadatan fitoplankton, terlebih dahulu dihitung volume air yang tersaring di dalam plankton net, digunakan rumus:

$$
\mathrm{V}=\pi \times r^{2} \times \mathrm{d}
$$

$$
\text { Dimana } \begin{aligned}
V & =\text { volume air yang tersaring } \\
\pi & =3,14 \\
r & =\text { diameter mulut plankton net }(20 \mathrm{~cm}) \\
d & =\text { panjang lintasan }(10 \mathrm{~m})
\end{aligned}
$$

Untuk menghitung kepadatan fitoplankton, menggunakan rumus menurut Cleseri dkk., dalam Palit 1997:

$$
E=\frac{c \times A}{f a \times V}
$$

$$
\begin{aligned}
\text { dimana : } & =\text { kepadatan fitoplankton (ind//tr) } \\
\mathrm{C} & =\text { total individu teramati } \\
\mathrm{A} & =\text { volume konsentrat fitoplankton } \\
\mathrm{fa} & =\text { volume cuplikan fitoplankton } \\
\mathrm{V} & =\text { volume sampel }
\end{aligned}
$$

\section{HASIL DAN PEMBAHASAN}

\section{Komposisi dan kelimpahan fitoplankton}

Penelitian yang telah dilaksanakan selama 3 bulan (Juni, Juli dan Agustus) ditemukan 32 genera dengan total individu 11.236 untuk keseluruhan lokasi yang terdiri dari 3 lokasi (Utara, Tengah dan Selatan).

Bila dilihat kelimpahan pada pengamatan setiap bulan, maka bulan Agustus merupakan bulan dengan kelimpahan yang lebih tinggi (4227 individu) dibanding bulan Juli (3.493 individu) dan bulan Juni (3.516 individu) Tabel 1 dan Gambar 1.

Hal ini diduga bulan Agustus merupakan musim kering, sehingga intensitas cahaya sangat mendukung keberadaan dari fitoplankton. Selain itu 2 bulan yang lain merupakan bulan dengan kondisi cuaca yang sering disertai mendung dan hujan. Hal ini juga dapat dijelaskan bahwa fitoplankton sangat membutuhkan cahaya. Dengan demikian tergambar bahwa bulan Agustus merupakan bulan dengan intensitas cahaya yang cukup untuk pertumbuhan fitoplankton.

Selain kelimpahan fitoplankton yang dilihat setiap bulan, juga dilihat kelimpahan setiap lokasi. Hasil analisis menunjukan bahwa lokasi utara (outlet) kelimpahan lebih tinggi dibanding 2 lokasi lainnya (Tabel 2 dan Gambar 1). Hal ini terjadi sebagai akibat dari massa air yang berpindah hanya menuju lokasi tersebut. Danau Tondano hanya memiliki 1 sungai sebagai outlet dari air danau. Selain itu angin yang bertiup ketiga bulan tesebut lebih didominasi angin selatan dan tenggara. 
Dengan demikian sesuai sifat plankton yang pergerakannya tergantung pada pergerakan massa air, maka lokasi utara merupakan tempat berkumpulnya plankton.

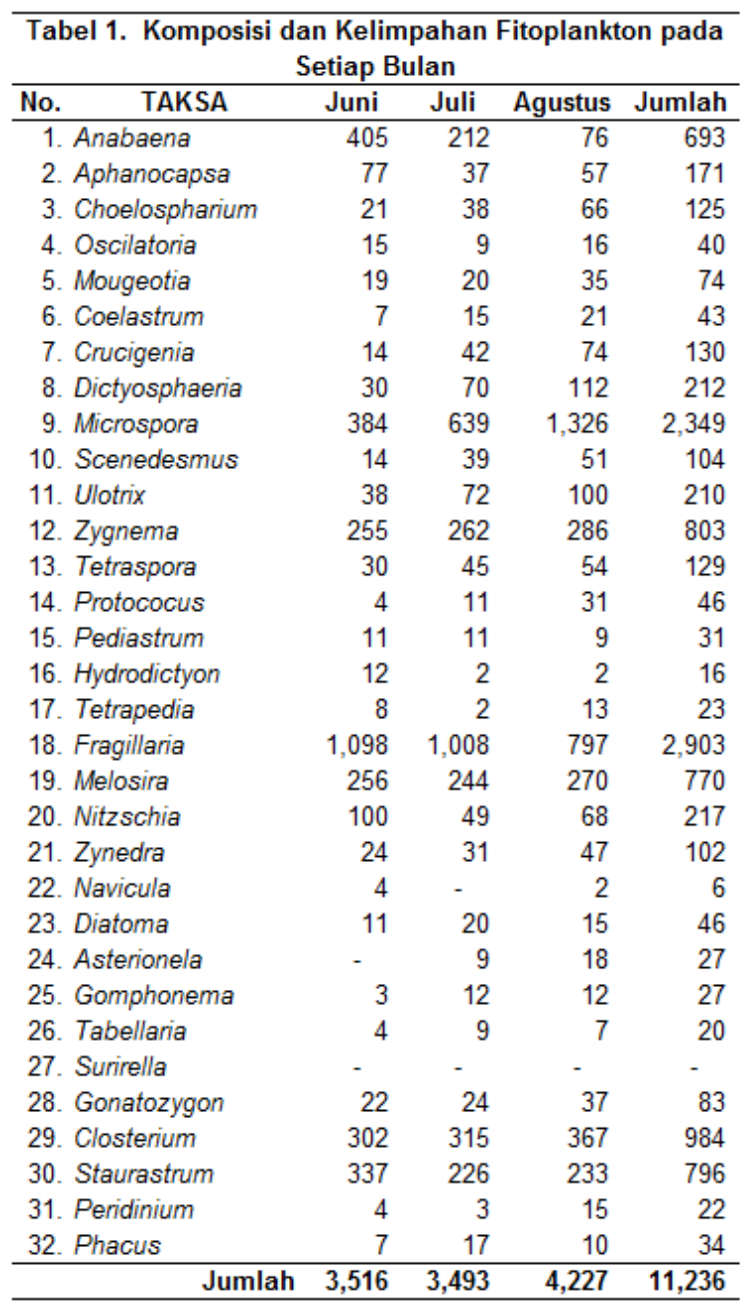

Tabel 2. Komposisi dan Kelimpahan Fitoplankton pada

Lokasi Penelitian

\begin{tabular}{lrrrr}
\hline No. TAKSA & Utara & Tengah & Selatan & Jumlah \\
\hline 1. Anabaena & 260 & 217 & 216 & 693 \\
2. Aphanocapsa & 52 & 63 & 56 & 171 \\
3. Choelospharium & 37 & 43 & 45 & 125 \\
4. Oscilatoria & 12 & 15 & 13 & 40 \\
5. Mougeotia & 26 & 26 & 22 & 74 \\
6. Coelastrum & 14 & 13 & 16 & 43 \\
7. Crucigenia & 48 & 41 & 41 & 130 \\
8. Dictyosphaeria & 72 & 71 & 69 & 212 \\
9. Microspora & 904 & 637 & 808 & 2,349 \\
10. Scenedesmus & 36 & 34 & 34 & 104 \\
11. Ulotrix & 72 & 68 & 70 & 210 \\
12. Zygnema & 277 & 261 & 265 & 803 \\
13. Tetraspora & 42 & 43 & 44 & 129 \\
14. Protococus & 14 & 14 & 18 & 46 \\
15. Pediastrum & 9 & 12 & 10 & 31 \\
16. Hydrodictyon & 6 & 7 & 3 & 16 \\
17. Tetrapedia & 8 & 8 & 7 & 23 \\
18. Fragillaria & 994 & 947 & 962 & 2,903 \\
19. Melosira & 242 & 270 & 258 & 770 \\
20. Nitzschia & 66 & 76 & 75 & 217 \\
21. Zynedra & 35 & 34 & 33 & 102 \\
22. Navicula & 6 & - & - & 6 \\
23. Diatoma & 12 & 19 & 15 & 46 \\
24. Asterionela & 10 & 8 & 9 & 27 \\
25. Gomphonema & 5 & 14 & 8 & 27 \\
26. Tabellaria & 5 & 6 & 9 & 20 \\
27. Surirella & - & - & - & - \\
28. Gonatozygon & 27 & 28 & 28 & 83 \\
29. Closterium & 360 & 296 & 328 & 984 \\
30. Staurastrum & 251 & 272 & 273 & 796 \\
31. Peridinium & 8 & 8 & 6 & 22 \\
32. Phacus & 12 & 10 & 12 & 34 \\
\hline & 3,922 & 3,561 & 3,753 & $\mathbf{1 1 , 2 3 6}$ \\
\hline & & & &
\end{tabular}
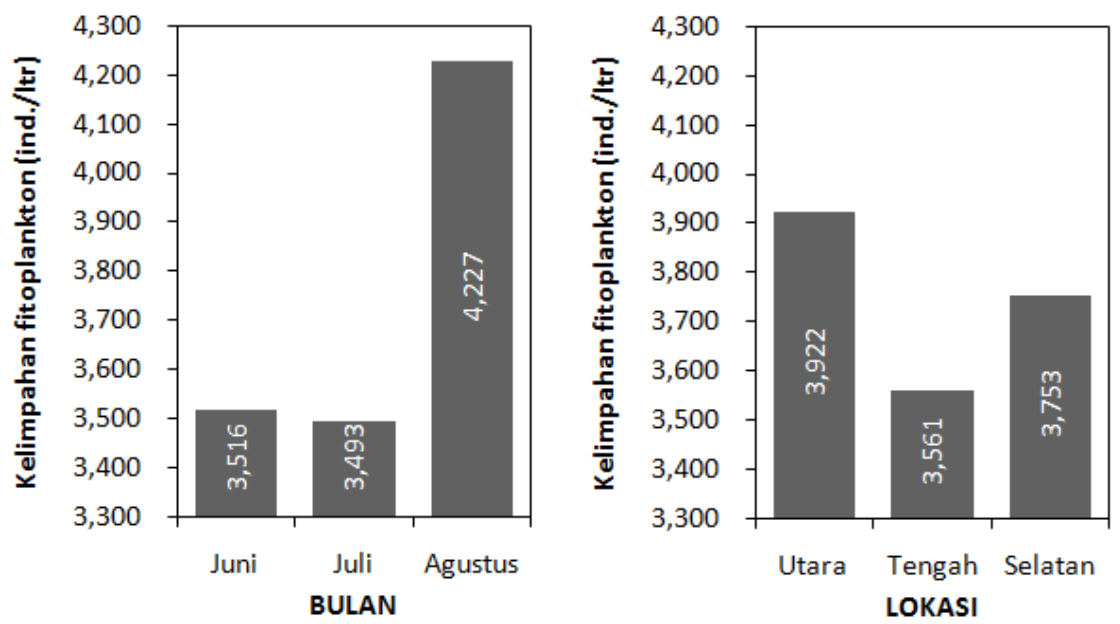

Gambar 1. Histogram kelimpahan setiap bulan dan lokasi

Jika dibandingkan dengan hasil penelitian Soeroto, dkk (1999) terjadi penurunan jumlah genera, dimana terjadi penurunan jumlah genera sebanyak 8 genera. Bila dibandingkan lagi dengan hasil penelitian tahun 1981 telah berkurang sebanyak 16 genera. Hal ini menunjukan bahwa danau Tondano memerlukan penangan yang serius. 


\section{KESIMPULAN}

Hasil penelitian selama 3 bulan yang dilaksanakan bulan Juni, Juli dan Agustus dapat disimpulkan sebagai berikut:

1. Ditemukan 32 genera fitoplankton selama penelitian.

2. Kelimpahan fitoplankton tertinggi berdasarkan lokasi dijumpai di lokasi outlet (lokasi utara)

3. Kelimpahan fitoplankton tertinggi berdasarkan bulan dijumpai pada bulan Agustus.

\section{DAFTAR PUSTAKA}

Apha. 1985. Standard Methods for the Examination of water and wastewater. $16^{\text {th }}$ Edition, American Public Health Association.Washington D.C.

Departemen Pekerjaan Umum Direktorat Jendral Sumberdaya Air. 2006. Rencana Pengelolaan Lingkungan Hidup (RKL) Bangunan Pengendali Banjir dan sediment Danau Tondano.

Davis, Charles C. 1955. The Marine and Freshwater Planktons. Michigan State University Press.

Kumurur, V.A., 2002, Aspek Strategis Pengelolaan Danau Tondano Secara Terpadu. Skripsi. Fakultas Teknik Universitas Sam Ratulangi. Manado.

Kementerian Lingkungan Hidup, 2006. Master Plan Pemulihan Kerusakan Lingkungan Danau Tondano.

Needham, J. G. dan P. R. Needham (1963). A Guide to the Study of Freshwater Biology. Published by Holden-Day, Inc., California.

Palit. M.G. 1997. Kepadatan dan Keanekaragaman Fitoplankton pada fase Bulan Berbeda di Perairan Likupang. Skripsi. Fakultas Perikanan Dan IImu Kelautan Universitas Sam Ratulangi. Manado.

Ratag, V. F. R. C. 1981. Suatu Penelitian Tentang Hubungan Antara Kepadatan dan Komposisi Phytoplankton dan Zooplankton di danau Tondano Kabupaten Minahasa Propinsis Sulawesi Utara. Manado.

Rondo, M. 1989. Dampak Pencemaran Terhadap Komunitas Biotik di Hulu dan Muara Sungai Tondano serta Perairan Sekitarnya. Jurnal Fak. Perikanan Vol. 1, No.1 Oktober 1989. Manado.

Sachlan, M. 1972. Planktonologi. Corespondence Course Centre. Direktorat Jendral Perikanan Depertemen Pertanian. Jakarta.

Soeroto, B., L.J.L Lumingas, S.B. Pratasik., F.F. Tilaar., F. Boneka,. J.F.W.S. Tamanampo., dan B. Poluan. 1999. Biota danau Dan sungai Tondano; Tinjauan Tentang Kualitas Perairan. Laporan Hasil Penelitian. Proyek Operasi Dan Pemeliharaan Danau Tondano Dan Limboto Di Kabupaten Minahasa Dan Gorontalo. Kerjasama Dinas Pekerjaan Umum Propinsis Sulawesi Utara dengan Fakultas Perikanan Dan IImu Kelautan Universitas Sam Ratulangi Manado Tahun 1999. 